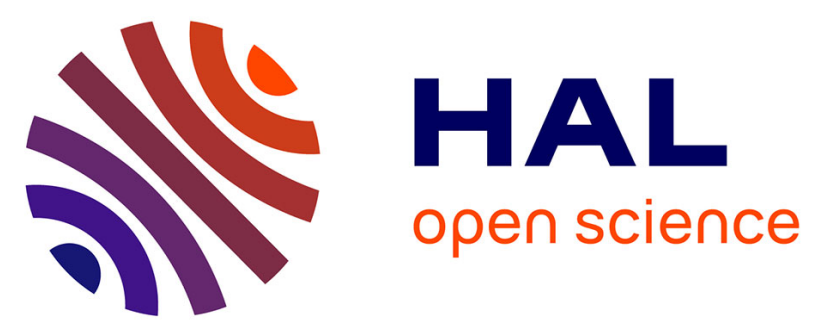

\title{
Quantitative Measurements of Composition, Pressure, and Density of Microvolumes of CO2 -N2 Gas Mixtures by Raman Spectroscopy
}

Van-Hoan Le, Marie-Camille Caumon, Alexandre Tarantola, Aurélien Randi, Pascal Robert, Josef Mullis

\section{- To cite this version:}

Van-Hoan Le, Marie-Camille Caumon, Alexandre Tarantola, Aurélien Randi, Pascal Robert, et al.. Quantitative Measurements of Composition, Pressure, and Density of Microvolumes of CO2 N2 Gas Mixtures by Raman Spectroscopy. Analytical Chemistry, 2019, 22 (22), pp.14359-14367. 10.1021/acs.analchem.9b02803 . hal-02345285

\section{HAL Id: hal-02345285 https://hal.science/hal-02345285}

Submitted on 20 Nov 2019

HAL is a multi-disciplinary open access archive for the deposit and dissemination of scientific research documents, whether they are published or not. The documents may come from teaching and research institutions in France or abroad, or from public or private research centers.
L'archive ouverte pluridisciplinaire HAL, est destinée au dépôt et à la diffusion de documents scientifiques de niveau recherche, publiés ou non, émanant des établissements d'enseignement et de recherche français ou étrangers, des laboratoires publics ou privés. 


\title{
Quantitative measurements of composition, pressure and density of micro-volumes of $\mathrm{CO}_{2}-\mathrm{N}_{2}$ gas mixtures by Raman spectroscopy
}

\author{
Van-Hoan Le * a, Marie-Camille Caumon ${ }^{\mathrm{a}}$, Alexandre Tarantola ${ }^{\mathrm{a}}$, Aurélien Randi ${ }^{\mathrm{a}}$, Pascal Robert ${ }^{\mathrm{a}}$ and \\ Josef Mullis ${ }^{\mathrm{b}}$ \\ ${ }^{\text {a }}$ Université de Lorraine, CNRS, GeoResssources Laboratory, BP 70239, F-54506 Vandoeuvre-lès-Nancy, France \\ ${ }^{\mathrm{b}}$ Mineralogisch-Petrographisches Institut, Bernoullistrasse 30, CH-4056 Basel, Switzerland \\ * Corresponding author: van-hoan.le@univ-lorraine.fr
}

\begin{abstract}
Quantitative analysis of gases by Raman spectroscopy is based on relative Raman scattering cross-sections (RRSCS) and the evolution of different spectral parameters (peak position, peak area, peak intensity, etc.). However, most of the calibration data were established at low pressure (low density) and without evaluating the effect of the composition. Using these data may lead to considerable errors, especially when applied to gas mixtures at high pressure as found in natural fluid inclusions. The aim of this study is to reevaluate the RRSCS of $\mathrm{CO}_{2}$ and to establish new calibration data based on the variation of $\mathrm{CO}_{2} \mathrm{Fermi}$ diad splitting as a function of pressure (density) and composition over a pressure range of 5 to 600 bars at 22 and $32{ }^{\circ} \mathrm{C}$. A high-pressure optical cell system (HPOC) and a heating-cooling stage were used for Raman in-situ analyses at controlled PTX conditions. Our experimental results show that the RRSCS of $\mathrm{CO}_{2}$ varies slightly with pressure but can be considered constant over the studied pressure range. It can be used to measure the proportion of $\mathrm{CO}_{2}$ in gas mixtures with an uncertainty of about $\pm 0.5 \mathrm{~mol} \%$. Different polynomial equations were provided to calculate pressure and density of $\mathrm{CO}_{2}-\mathrm{N}_{2}$ gas mixtures with an uncertainty of \pm 20 bar or $0.01 \mathrm{~g} . \mathrm{cm}^{-3}$. A comparison of PVTX properties of natural $\mathrm{CO}_{2}-\mathrm{N}_{2}$ fluid inclusions hosted in quartz from the Central Alps (Switzerland) obtained by Raman measurement and as derived from phase transition temperatures by microthermometry experiments shows comparable values.
\end{abstract}

The exploration of the Raman effect by C.V Raman in 1928 provided a new way for non-destructive analyses of materials under different phase states (solid, liquid and gaseous) to get qualitative and quantitative information (after establishing calibration data). The sensitivity of Raman spectroscopy covers a wide concentration range, down to very low concentration, ${ }^{1,2}$ even to sub-ppm levels ${ }^{3,4}$. Raman spectroscopy has been widely used for gas analysis in various domains of investigation such as monitoring of polluted air ${ }^{5}$ or automobile exhaust gases, ${ }^{1}$ fuel gas analysis, ${ }^{6-8}$ diagnosis and monitoring of disease states by human breath analysis, ${ }^{3,4,9}$ controlling and monitoring of fruit ripening, ${ }^{10}$ analyzing of gas bubbles appearing as defects inside industrial glasses to optimize production process. ${ }^{11}$ Other applications can also be found in the field of environmental gas sensing, e.g. monitoring of geological storage site of $\mathrm{CO}_{2},{ }^{12}$ investigation of biological and/or geochemical gas exchange and migration processes within the different compartment (groundwater, subsurface, surface, atmosphere) ${ }^{13-17}$ All applications mentioned above relate exclusively to the analysis of immense and/or small volume of gas at relatively low pressure $(<$ few dozen bars). The present study is dedicated to another case of extreme conditions: the analysis of gas mixtures in micro-volumes at relatively high pressure (up to 600 bar). The main application is the study of fluid inclusions naturally trapped in minerals.

Fluid inclusions (FIs) are small cavities in minerals containing a micro-volume of a geological fluid trapped during or after crystal growth. They are the most reliable relicts recording information about the conditions of crystal formation as well as of paleo-fluid circulations. A quantitative knowledge (composition, pressure, and density) of these fluids provides key information to better understand geological processes, to reconstruct the conditions of paleo-fluid circulations and thereafter for further application such as natural resources exploration. ${ }^{18} \mathrm{CO}_{2}$ and $\mathrm{N}_{2}$ are among the most common gases present in a large variety of geological fluids. ${ }^{18,19}$

The observation of phase transitions during microthermometry experiments is currently the standard method to investigate fluid inclusion properties. However, some limitations appear when FIs are of small size $(<5 \mu \mathrm{m})$, of complex composition or of low density without any observable phase transitions. ${ }^{20-24}$ Raman spectroscopy is a complementary method to microthermometry as it can offer fast (from a few seconds to a few minutes), high resolution (down to $\sim 1 \mu \mathrm{m}^{2}$ ) and simultaneous non-destructive, qualitative and quantitative analyses. ${ }^{25-27} \mathrm{Sev}-$ eral applications of Raman spectroscopy dedicated to the investigation of FIs have been carried out by different research teams since the 1970 s (cf. reviews by Burke ${ }^{25}$ and Frezzotti et al. ${ }^{26}$ ). The determination of the composition, pressure, and density of gas mixtures using Raman spectroscopy requires the knowledge of the Raman scattering cross-section (RSCS) and the behavior of Raman spectral features (peak position, peak area/intensity ratio...) as a function of pressure, density, temperature, and composition. ${ }^{25,26}$

RSCS is a specific parameter related to the probability of Raman scattering effect for each vibration. It can be used to determine the concentration of molecules. ${ }^{28}$ Due to the difficulty of the determination of absolute values of RSCS, only that of $\mathrm{N}_{2}$ was carefully determined by different techniques. ${ }^{29-32}$ Relative RSCS (RRSCS) values of common gaseous species found in fluid inclusions $\left(\mathrm{CO}_{2}, \mathrm{CO}, \mathrm{CH}_{2}, \mathrm{O}_{2}, \mathrm{H}_{2} \mathrm{~S} \ldots\right)$ were then measured relatively to RSCS of $\mathrm{N}_{2}$ with an accuracy varying from 5 to 20 $\%$. ${ }^{25,32}$ However, all published data of RRSCS were determined at room temperature and 1 - 5 atm whereas, according to 
Wopenka et Pasteris ${ }^{28}$ and Seitz et al. ${ }^{33,34}$ RRSCS may not just vary as a function of wavelength and temperature, ${ }^{32}$ but also as a function of pressure and composition due to changes in molecular interaction. ${ }^{35}$ Moreover, although many improvements in Raman instruments were made, the RRSCS data were never reevaluated since the 1970 s.

The variations of the peak positions of Raman bands of $\mathrm{N}_{2}$ and $\mathrm{CO}_{2}$ as a function of pressure (or density) were also separately investigated, ${ }^{20,21,24,36-41}$ showing the applicability for pressure and density monitoring. Indeed, the Fermi diad splitting (distance between the two main peaks) of $\mathrm{CO}_{2}$ was used to develop densimeters for pure $\mathrm{CO}_{2}$ or $\mathrm{CO}_{2}$-rich fluid inclusions. ${ }^{20,21,24,37,39,40,42,43}$ Nevertheless, the variation of peak positions as well as of $\mathrm{CO}_{2}$ Fermi diad splitting are subject to changes as a function of pressure, density, temperature ${ }^{39,40}$ but also composition. ${ }^{33,34,40}$ The inappropriate use of calibration data obtained from pure gas for analyzing gas mixtures may, therefore, lead to an over/underestimation of density ${ }^{40}$ or pressure. ${ }^{41}$ Thus, the effect of composition, pressure, density, and temperature on Raman spectral features should be simultaneously taken into account upon any quantitative analysis. The experimental data of Seitz et al. ${ }^{33,34}$ revealed the variation trends of different Raman spectral features of $\mathrm{CO}_{2}$ and $\mathrm{N}_{2}$ as a function of composition (when mixed with $\mathrm{CH}_{4}$ ) but the results were quite scattered due to the use of low spectral resolution $\left(\sim 5 \mathrm{~cm}^{-}\right.$ $\left.{ }^{1}\right)$. Consequently, no robust calibration with uncertainty analysis was given.

The present work aims (1) to reevaluate the dependence of RRSCS of $\mathrm{CO}_{2}$ on pressure and composition by using nowadays performance instruments and (2) to establish a new Raman calibration methodology for composition, pressure, and density measurement of any $\mathrm{CO}_{2}-\mathrm{N}_{2}$ gas mixtures. Data acquisition was done thanks to the combination of an improved HPOC system $^{44-46}$ and a heating-cooling stage to control the $P T$ conditions during experiments and to collect numerous data points for statistical purposes. $\mathrm{CO}_{2}-\mathrm{N}_{2}$ gas mixtures of different compositions were analyzed by Raman spectroscopy at $22{ }^{\circ} \mathrm{C}$ (room temperature) and $32{ }^{\circ} \mathrm{C}$ (just above the critical point of pure $\mathrm{CO}_{2}$ in order to avoid any $\mathrm{V}-\mathrm{L}$ phase transition for any $\mathrm{CO}_{2}-\mathrm{N}_{2}$ mixture composition) over the pressure range 5 - 600 bar. The relationships between the variation of Raman spectral parameters with pressure (or density) and composition were evaluated to determine the most reliable quantification parameters. Finally, the composition, density, and pressure of natural FIs hosted in quartz from the Central Alps (Switzerland) ${ }^{47}$ were obtained with these calibration data, and subsequently compared with microthermometry data.

\section{MATERIALS AND METHODS}

Gas mixture preparation. $\mathrm{CO}_{2}-\mathrm{N}_{2}$ binary mixtures of different compositions were prepared from high-purity commercial $\mathrm{N}_{2}$ and $\mathrm{CO}_{2}$ gases (99.99\% purity, Air Liquide ${ }^{\mathrm{TM}}$ ) at low pressure $\left(<10\right.$ bar) by a gas mixer (GasMix AlyTech $\left.{ }^{\mathrm{TM}}\right)$. They were subsequently compressed up to $120-150$ bars using a home-made compressor system and stored in a stainless-steel reservoir. The composition of the prepared gas mixtures was controlled by gas chromatography (GC) to ensure there was no significant modification during the compression step. The GC was calibrated by measuring several times a commercial $\mathrm{CO}_{2-}$ $\mathrm{N}_{2}$ gas mixture (Air Liquide ${ }^{\mathrm{TM}}$ ), yielding a standard deviation of about $0.4 \mathrm{~mol} \%$. The final composition of the prepared gas mixtures was the average of three GC measurements with a standard uncertainty $\sim \frac{0.4}{\sqrt{3}} \approx 0.3 \mathrm{~mol} \%(1 \sigma)$. The compositions of the $\mathrm{CO}_{2}-\mathrm{N}_{2}$ gas mixtures used in this study were $10.5,30.1$, $50.3,60.9,70.5,80.1$, and $88.6 \mathrm{~mol} \% \mathrm{CO}_{2}$.

Pressurization system. The reservoir containing the gas mixture was connected to an improved HPOC system, which consists of several valves, stainless steel microtubes and a pump (Figure 1). ${ }^{44-46}$ One end of the HPOC system was equipped with a manual screw pressure generator. The other end was coupled with a fused silica capillary (FSC) of $200 \mu \mathrm{m}$ of internal diameter sealed at one end by a hydrogen flame. ${ }^{46,48}$ Two pressure transducers were set on the fixed part and on the movable part of the HPOC system to monitor pressure $( \pm 1$ bar) inside the whole system. The FSC was set on a customized heating-cooling stage (Linkam CAP500) previously calibrated by measuring the triple point of distilled water $\left(0.0^{\circ} \mathrm{C}\right)$ and of a pure $\mathrm{CO}_{2}$ standard sample $\left(-56.6^{\circ} \mathrm{C}\right)$ to maintain the temperature at 22.0 and $32.0 \pm 0.1^{\circ} \mathrm{C}$. The system was evacuated for a minimum of 30 minutes to remove any other gases before loading the investigated gas mixture. Thereby, the gas mixtures were analyzed by Raman spectroscopy through the microcapillary at controlled $P T$ conditions.

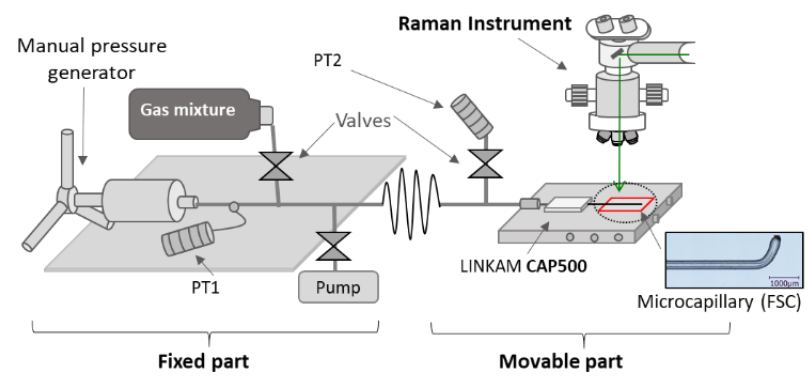

Figure 1: Sketch of the HPOC system coupled with a transparent fused silica capillary (FSC) set on a Linkam CAP500 heating-cooling stage. The system consists of a fixed part composed of a manual pressure generator, a pressure transducer (PT1), valves, microtubes, and a pump to purge the system. The movable part connects the system with the heating-cooling stage. It is also equipped with valves and another pressure transducer (PT2).

Raman spectroscopy. Raman measurements were performed using a LabRAM HR spectrometer (Horiba JobinYvon() equipped with an 1800 groove $\cdot \mathrm{mm}^{-1}$ grating with an aperture of confocal hole and slit set at $1000 \mu \mathrm{m}$ and $200 \mu \mathrm{m}$, respectively, giving a spectral resolution of about $1.67 \mathrm{~cm}^{-1}$ (fitted FWHM of Neon peak at $\left.2348 \mathrm{~cm}^{-1}\right)$. The excitation radiation was provided by an $\mathrm{Ar}^{+}$laser (Stabilite 2017, Spectra-Physics) at $514.53 \mathrm{~nm}$ with a power of $200 \mathrm{~mW}$, focused on the FSC by a $20 \mathrm{X}$ objective (Olympus, NA $=0.4$ ). Each measurement was repeated six times successively at the same $P T X$ conditions for statistical purposes. A spectrum was recorded before loading any gas mixture into the microcapillary to measure the contribution of atmospheric $\mathrm{N}_{2}$ for peak area correction. ${ }^{35}$ The same configuration (excitation wavelength, hole, slit, grating) was used for Raman analyses of natural FIs, except the use of a 50 $\mathrm{X}$ objective (Olympus, $\mathrm{NA}=0.5$ ). To minimize the error due to the subtraction of the $\mathrm{N}_{2}$ peak area, the intensity of the $\mathrm{N}_{2}$ band within FI should be 3 or 4 times higher than that of ambient $\mathrm{N}_{2}$. Thus, the acquisition time ranged from 5 to 30 seconds per accumulation (with 10 accumulations per measurement) depending on the density, size, shape, and depth of FIs. 

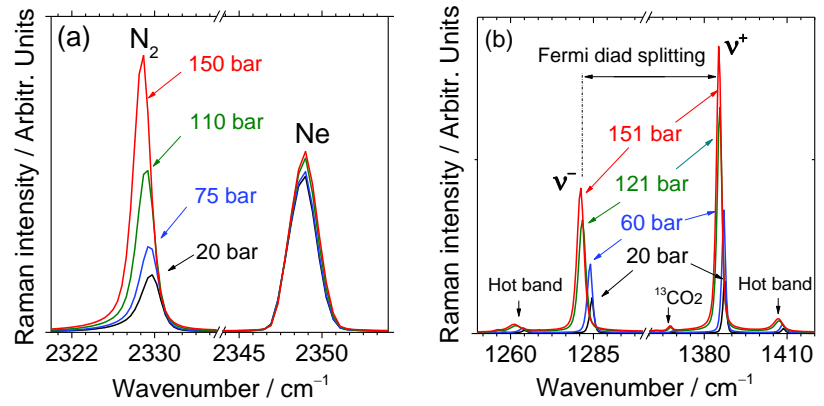

Figure 2: Evolution of (a) $\mathrm{N}_{2}$ and (b) $\mathrm{CO}_{2}$ Raman spectra with pressure. Both gases show a downshift with increasing pressure. The signal of neon $(\mathrm{Ne})$ was simultaneously recorded with $\mathrm{N}_{2}$ spectra for wavenumber calibration.

The Raman spectrum of $\mathrm{N}_{2}$ characterized by a peak at $\sim 2331$ $\mathrm{cm}^{-1}$ was simultaneously recorded with Ne peak at $\sim 2348 \mathrm{~cm}^{-1}$ (Figure 2a) for wavelength calibration. ${ }^{49}$ As the $\mathrm{N}_{2}$ band is not symmetrical (due to the asymmetric distribution of $\Delta \mathrm{J}=0$ transition in the Q-branch ${ }^{50}$ ), the spectra of $\mathrm{N}_{2}$ were fitted by an asymmetrical Gaussian-Lorentzian function using the peak fitting tool of LabSpecs 6 software (Horiba) after baseline subtraction. The peak position of $\mathrm{N}_{2}$ was then corrected by that of $\mathrm{Ne}$ using Equation 1, where $v_{\mathrm{N}_{2}}$ and $v_{\mathrm{Ne}}$ are the fitted peak positions of $\mathrm{N}_{2}$ and $\mathrm{Ne}$, respectively, and $2348.4318 \mathrm{~cm}^{-1}$ the reference peak position of $\mathrm{Ne}$ cited from NIST webbook. ${ }^{51}$

$v_{N_{2}(\text { cor })}=v_{N_{2}}+\left(2348.4318-v_{N e}\right)$

$\mathrm{CO}_{2}$ has four vibrational modes: symmetrical stretching $\left(v_{1}\right)$, asymmetrical stretching $\left(v_{3}\right)$ and a doubly degenerated bending mode $\left(v_{2 \mathrm{a}}\right.$ and $\left.v_{2 \mathrm{~b}}\right)$. Only the $v_{1}$ mode $\left(\sim 1333 \mathrm{~cm}^{-1}\right)$ is Ramanactive. However, the experimental spectrum of $\mathrm{CO}_{2}$ presents two strong bands because of Fermi resonance ${ }^{52}$ taking place between the excited vibrational states $v_{1}$ and the first overtone of $v_{2}\left(2 v_{2}=2 \times 667=1334 \mathrm{~cm}^{-1}\right)$. As these two excited states have nearly the same energy level, they perturb each other and cause a division into two peaks at higher $\left(1388 \mathrm{~cm}^{-1}\right)$ and lower $\left(1285 \mathrm{~cm}^{-1}\right)$ wavenumbers. This phenomenon is known as the Fermi diad splitting, resulting in two bands denoted $v^{+}$and $v^{-}$, respectively. Moreover, the spectrum of $\mathrm{CO}_{2}$ has also two lowintensity bands at $1409 \mathrm{~cm}^{-1}$ and $1265 \mathrm{~cm}^{-1}$, known as hot bands. Another weak band at $1370 \mathrm{~cm}^{-1}$ corresponds to the signal of ${ }^{13} \mathrm{CO}_{2}$ (Figure 2b). Extended interpretation of spectral features of $\mathrm{CO}_{2}$ can be found in literature. ${ }^{53}$ Raman spectra of $\mathrm{CO}_{2}$ were fitted by symmetric Gaussian-Lorentzian function using LabSpec 6 (Horiba) after baseline subtraction. Final values of spectral parameters were the mean of 6 measurements, yielding an uncertainty of about $\pm 0.4 \%(1 \sigma)$ for peak area values, about $\pm 0.01 \mathrm{~cm}^{-1}(1 \sigma)$ for peak position and $\pm 0.015 \mathrm{~cm}^{-1}$ for $\mathrm{CO}_{2}$ Fermi diad splitting $(1 \sigma)$ (see Supporting Information for detailed uncertainty calculations).

The Raman spectra of $\mathrm{CO}_{2}$ and $\mathrm{N}_{2}$ were recorded in two different spectral ranges (1100 to $1580 \mathrm{~cm}^{-1}$ and 2100 to 2525 $\mathrm{cm}^{-1}$, respectively) with different instrumental efficiency of the spectrometer. ${ }^{27}$ All the Raman spectra were thus corrected using an ICS function (Intensity Correction System) integrated into LabSpec 6 software to normalized instrument response with wavelength. The calibration was done using a white lamp of known emission (Raman Calibration Accessory, Kaiser Optical Systems, Inc.). ${ }^{27}$ As a result, the instrumental efficiencies at the wavelength of $\mathrm{CO}_{2}$ and $\mathrm{N}_{2}$ peaks $\left(\xi_{\mathrm{CO}_{2}}\right.$ and $\left.\xi_{\mathrm{N}_{2}}\right)$ can be considered identical.
Microthermometry. Microthermometry is a standard method to determine PVTX proprieties of natural FIs. It is based on the determination of phase transition temperatures of geological fluid trapped within inclusions. In the present work, microthermometry measurements of natural FIs were made using a THMSG600 heating-cooling stage coupled with an Olympus BX50 microscope. The stage was calibrated at $\pm 0.1{ }^{\circ} \mathrm{C}$ using standard inclusions against the melting point of pure $\mathrm{CO}_{2}$ $\left(-56.6{ }^{\circ} \mathrm{C}\right)$ and of pure $\mathrm{H}_{2} \mathrm{O}\left(0.0{ }^{\circ} \mathrm{C}\right)$. Herein, the melting temperature $T_{m}$ (car) and the homogenization temperature $T_{h}$ (car) of the volatile carbonic phase containing the $\mathrm{CO}_{2}-\mathrm{N}_{2}$ mixtures trapped within FIs were measured. These phase transition temperatures were then used to determine the composition and density of FIs using the $V X$ diagram of Thiéry et al. ${ }^{54}$

GERG-2004 equation of state (EoS) is used to calculate (i) the pressure within natural FIs at a given temperature from density-composition properties derived from microthermometry results and (ii) the density of gas mixtures during Raman measurements (for a given composition, pressure and temperature). The GERG-2004 EoS is known as the most accurate available EoS at the $P$ and $T$ conditions of interest. Concerning the $\mathrm{CO}_{2-}$ $\mathrm{N}_{2}$ gas mixtures, the EoS is fitted from 823 experimental data points, covers the entire composition range (from 1 to $98 \mathrm{~mol} \%$ in $\mathrm{CO}_{2}$ ) and large pressure and temperature ranges ( 1 to 2740 bars and -63 to $400{ }^{\circ} \mathrm{C}$ ). The uncertainties in density are shown to be less than $0.1 \%$ when pressure $<350$ bars or less than 0.5 $\%$ when pressure $<700$ bars in the vapor region, about $0.1-0.5$ $\%$ in the liquid region and less than $3 \%$ in the two-phase region. This model is integrated into REFPROP software..$^{55}$

Natural fluid inclusions. A prismatic quartz crystal $(\mathrm{Mu}$ 147.2) found in late Alpine tension gashes from the Central Alps (Switzerland) ${ }^{47}$ was used for its $\mathrm{CO}_{2}-\mathrm{N}_{2}$ natural fluid inclusions. At room temperature, the 2 to $30 \mu \mathrm{m}$ large FIs are either monophasic (liquid $\mathrm{CO}_{2}+\mathrm{N}_{2}$ ) or biphasic (liquid $\mathrm{H}_{2} \mathrm{O}+\mathrm{va}-$ por $\mathrm{CO}_{2}-\mathrm{N}_{2}$ ) (Figure 3). 15 FIs from 4 different zones were selected to be analyzed by Raman spectroscopy and microthermometry for comparison.
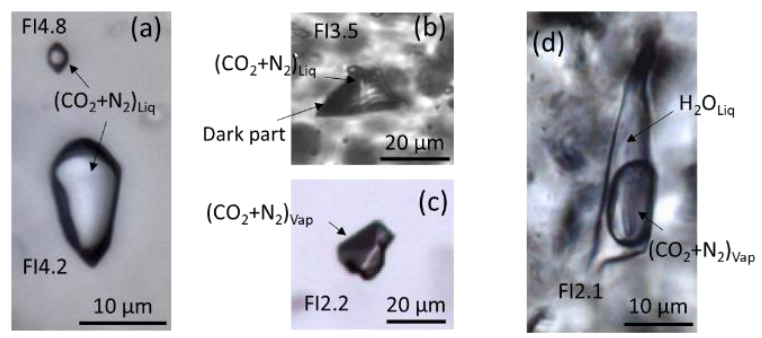

Figure 3: Examples of selected FIs of sample $\mathrm{Mu} 147.2$ (transmitted plane-polarized light at room temperature): (a), (b) and (c) monophasic FIs from zones 4,3 and 2 containing a $\mathrm{CO}_{2}-\mathrm{N}_{2}$ liquid phase; (d) two-phase FI containing $\mathrm{H}_{2} \mathrm{O}$ (liquid) and a bubble of $\mathrm{CO}_{2}-\mathrm{N}_{2}$ vapor.

\section{RESULTS AND DISCUSSION}

Mixture composition: Evaluation of the RRSCS of $\mathrm{CO}_{2}$. The RRSCS of the two main bands of $\mathrm{CO}_{2}\left(\sigma_{\mathrm{CO}_{2}}\right)$ were calculated at different composition and pressure conditions with the use of Equation 2, ${ }^{28}$ where $A_{\mathrm{CO}_{2}}$ is the peak area of $\mathrm{v}^{+}$or $\mathrm{v}^{-}$band, $A_{N_{2}}$ is the peak area of the $\mathrm{N}_{2}$ band, $C_{C_{2}}$ and $C_{N_{2}}$ are the concentration $(\mathrm{mol} \%)$ of $\mathrm{CO}_{2}$ and $\mathrm{N}_{2}$, respectively.

Figure 4a shows the variation of the RRSCS of the upper band $\left(\sigma_{v^{+}}\right)$and the lower band $\left(\sigma_{v^{-}}\right)$as a function of pressure and composition. Both RRSCS are somewhat perturbed at low pressure $(<\sim 80$ bars $)$, probably due to a significant change of 
molecular interaction effect. ${ }^{33,34}$ Above $\sim 80$ bars, $\sigma_{v^{+}}$increases slightly whereas $\sigma_{v^{-}}$decreases slightly with increasing pressure. Indeed, from 5 to 600 bars, the RRSCS value only increases by $0.05\left(\sigma_{v^{+}}\right)$or decrease by $0.1\left(\sigma_{v^{-}}\right)$, resulting in a difference of only $\sim 0.2 \mathrm{~mol} \% \mathrm{CO}_{2}$. Figure $4 \mathrm{~b}$ shows the evolution of the sum of the two RRSCS of $\mathrm{CO}_{2}\left(\sigma_{v^{+}}+\sigma_{v^{-}}\right)$as a function of pressure and composition. A slight perturbation was also observed at a low pressure-range. Above 80 bars, it remains nearly constant up to 600 bars for every composition.

$$
\sigma_{\mathrm{CO}_{2}}=\frac{A_{\mathrm{CO}_{2}} \cdot C_{N_{2}}}{A_{N_{2}} \cdot C_{\mathrm{CO} 2}}
$$
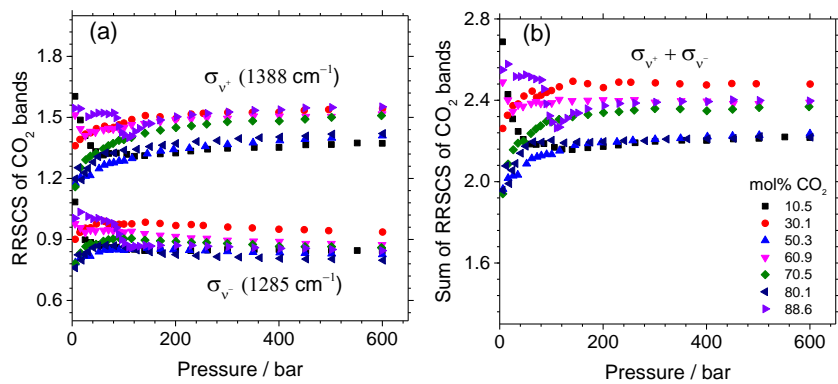

Figure 4: Variation as a function of pressure and composition of (a) the RRSCS of the two bands of $\mathrm{CO}_{2}\left(\sigma_{v+}\right.$ at $1388 \mathrm{~cm}^{-1}$ and $\sigma_{v-}$ at $\left.1285 \mathrm{~cm}^{-1}\right)$ and $(\mathrm{b})$ their sum $\left(\sigma_{v_{+}}+\sigma_{v_{-}}\right)$.

A small shift with composition is observed but without a clear correlation (Figure $4 \mathrm{a}$ and $4 \mathrm{~b}$ ). The shifts are quite small, which is probably due to the small error on the measured composition of gas mixtures and to the sensitivity of the Raman spectrometer. Indeed, each gas mixture was analyzed on a different day, and there is always a fluctuation in the instrumental efficiency from day to day (known as instrumental and random errors).

Table 1: RRSCS of the two bands of $\mathrm{CO}_{2}\left(v^{+}\right.$and $\left.v^{-}\right)$and their sum. Values in literature were obtained at low pressure (1$5 \mathrm{~atm})$ and room temperature. Our data are obtained in the pressure range $5-600$ bar at $32{ }^{\circ} \mathrm{C}$.

\begin{tabular}{|c|c|c|c|c|}
\hline & This study & Ref. $^{29}$ & Ref. $^{30}$ & Ref. $^{31}$ \\
\hline$\lambda(\mathrm{nm})$ & 514 & 514 & 514 & 488 \\
\hline Pressure (bar) & $5-600$ & 2.35 & - & $\leq 1$ \\
\hline$\sigma_{v+}$ & $1.40 \pm 0.03$ & 1.5 & $1.37 \pm 0.1$ & 1.4 \\
\hline$\sigma_{v-}$ & $0.89 \pm 0.02$ & 1 & - & 0.89 \\
\hline$\sigma_{v+}+\sigma_{v-}$ & $2.29 \pm 0.04$ & 2.5 & - & 2.29 \\
\hline
\end{tabular}

Dubessy et al. ${ }^{35}$ stated that the sum of two RRSCS of $\mathrm{CO}_{2}$ should always be preferred for the determination of gas mixture composition because it is constant with pressure. However, Seitz et al. ${ }^{34}$ showed in figure 5 that it was advantageous to use $\sigma_{v^{+}}$only rather than the sum of the two for determining the composition of gas mixtures. According to our statistical analyses, the small variations of $\sigma_{v^{+}}$and $\sigma_{v^{-}}$with pressure are negligible. We can, therefore, conclude that $\sigma_{v^{+}}, \sigma_{v^{-}}$and their sum are all almost constant for every gas mixture concentration over the studied pressure range and can be therefore be used to determine the composition of the gas mixture. However, the small variations of $\sigma_{v^{+}}$and $\sigma_{v^{-}}$may become significant at very high pressure. The sum of the two RRSCS of $\mathrm{CO}_{2}$ should, therefore, be used in preference to avoid any effect of pressure. The averaged values calculated from the experimental data (a population of 160 data points) are $1.40 \pm 0.03,0.89 \pm 0.02$ and $2.29 \pm 0.04$, for $v^{+}, v^{-}$and the sum $v^{+}+v^{-}$, respectively (uncertainties at $1 \sigma$ ). The values are in agreement with the data from literature but are given with better accuracy (Table 1).
Effect of composition, pressure, and density on Raman spectral features of $\mathrm{N}_{2}$ and $\mathrm{CO}_{2}$

a. Variation of the $\mathrm{N}_{2}$ peak position at $32{ }^{\circ} \mathrm{C}$

The downshift of the $\mathrm{N}_{2}$ band as a function of pressure and composition is shown in Figure $2 \mathrm{a}$ and Figure 5. The uncertainty of the corrected peak position of $\mathrm{N}_{2}\left( \pm 0.01 \mathrm{~cm}^{-1}\right)$ is too small to be shown in Figure 5. At low pressure, the $\mathrm{N}_{2}$ peak position seems to converge to the same value $(\sim 2330-2330.5$ $\mathrm{cm}^{-1}$ ) for all gas compositions that is in agreement with Lamadrid et al. ${ }^{43}$ A drastic downshift is reported from 5 to 200 bars, especially for the gas mixtures dominated by $\mathrm{CO}_{2}$. Above 200 bars, it becomes less sensitive to pressure, even becoming nearly constant for gas mixtures dominated by $\mathrm{CO}_{2}$. This stepwise behavior can be explained by the variation of the density of the gas mixtures. For example, the density of the mixture at $11.4 \mathrm{~mol} \% \mathrm{~N}_{2}$ increases drastically from 5 to 200 bar then reaches a plateau until 600 bar (cf. Figure S1). Figure 5 shows that the peak positions of $\mathrm{N}_{2}$ also vary with the composition of gas mixtures. In general, the presence of $\mathrm{CO}_{2}$ causes a greater downshift of the $\mathrm{N}_{2}$ peak position than that of pure $\mathrm{N}_{2}$ at the same pressure. For instance, a downshift of about $2 \mathrm{~cm}^{-1}$ is observed for pure $\mathrm{N}_{2}$ at 600 bars, whereas it is about $3.4 \mathrm{~cm}^{-1}$ for a gas mixture of $11.4 \mathrm{~mol} \% \mathrm{~N}_{2}$.

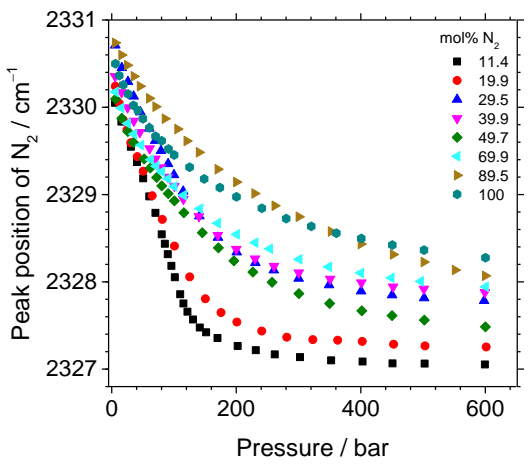

Figure 5: Variation of the fitted peak position of $\mathrm{N}_{2}$ (corrected from Ne peak position) at $32{ }^{\circ} \mathrm{C}$ as a function of pressure and composition $\left(\mathrm{mol}_{\mathrm{O}} \mathrm{N}_{2}\right)$ of gas mixtures.

Besides, some curves relative to samples at different $\mathrm{N}_{2}$ concentrations are superimposed or overlap each other (100 and $89.5 \mathrm{~mol} \% \mathrm{~N}_{2}$ or $29.5,39.9$ and $69.9 \mathrm{~mol} \% \mathrm{~N}_{2}$ ), indicating that the variation of the peak position of $\mathrm{N}_{2}$ as a function of composition is not significant enough to be distinguished for some composition-pressure ranges. Moreover, for unknown reasons, the $89.5 \% \mathrm{~N}_{2}$ curve shows an abnormal behavior whereas the corresponding associated curve of the Fermi diad splitting of $\mathrm{CO}_{2}$ (the curve of $10.5 \mathrm{~mol} \% \mathrm{CO}_{2}$ in Figure 6) evolves as expected. The modest reproducibility of the $\mathrm{N}_{2}$ peak position despite wavelength calibration by Ne may be linked to small dayto-day variation in the shape and the position of the neon band because of variations in the positioning of the neon lamp in the optical path of the Raman spectrometer. Thus, a higher-accurate method to wavelength correction is required to use the $\mathrm{N}_{2}$ peak position as a reliable quantitative parameter. After all, we can only conclude here the global variation trend of the $\mathrm{N}_{2}$ peak position with a significant effect of the composition and pressure.

b. Variation of the $\mathrm{CO}_{2}$ Fermi diad splitting at $32^{\circ} \mathrm{C}$

Figure $2 \mathrm{~b}$ shows typical Raman spectra of $\mathrm{CO}_{2}$ and the downshift of $\mathrm{CO}_{2}$ peaks with increasing pressure. The two bands of $\mathrm{CO}_{2}$ were investigated by measuring the distance between them (Fermi diad splitting), so there was no need for absolute wavelength calibration of the spectrometer. 


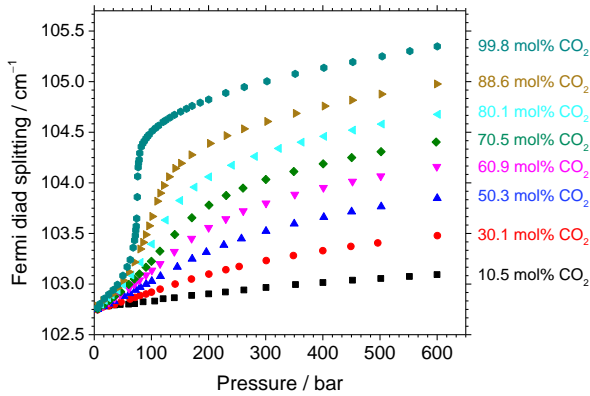

Figure 6: Evolution of the Fermi diad splitting as a function of composition and pressure of different $\mathrm{CO}_{2}-\mathrm{N}_{2}$ gas mixtures at $32{ }^{\circ} \mathrm{C}$. Uncertainties of Fermi diad splitting $\left( \pm 0.015 \mathrm{~cm}^{-1}\right.$ at $\left.1 \sigma\right)$ and of pressure ( \pm 1 bar) are smaller than the data dot size.

Figure 6 represents the variation of the Fermi diad splitting of $\mathrm{CO}_{2}$ at $32{ }^{\circ} \mathrm{C}$ as a function of pressure and composition of the $\mathrm{CO}_{2}-\mathrm{N}_{2}$ gas mixture. At low pressure, the Fermi diad splitting value is nearly identical $\left(\sim 102.762 \mathrm{~cm}^{-1}\right)$ for any composition. At higher pressure, an effect of the gas mixture composition is clearly observed. In general, the presence of $\mathrm{N}_{2}$ reduces the magnitude of the variation of the Fermi diad splitting. For example, at 600 bars, the Fermi diad splitting shifts down from $105.348 \mathrm{~cm}^{-1}$ (for pure $\mathrm{CO}_{2}$ ) to $103.093 \mathrm{~cm}^{-1}$ (for the gas mixture at $10.5 \mathrm{~mol} \% \mathrm{CO}_{2}$ ). This trend is relatively similar to that observed for $\mathrm{CO}_{2}$ mixed with $\mathrm{CH}_{4}{ }^{34}$ The repeatability and the reproducibility of the relationship between Fermi diad splitting, pressure, and composition of the gas mixture are much better than the peak position of $\mathrm{N}_{2}$ (Figure 5). The Fermi diad splitting of $\mathrm{CO}_{2}$ can thus be used as an accurate parameter to determine the pressure of $\mathrm{CO}_{2}-\mathrm{N}_{2}$ gas mixtures.

The Fermi diad splitting of $\mathrm{CO}_{2}$ can also be used for the determination of the density of $\mathrm{CO}_{2}-\mathrm{N}_{2}$ gas mixtures. For this, the density of every gas mixtures at given $P T$ conditions presented in Figure 6 was calculated by the GERG-2004 EoS. The resulting relationship between Fermi diad splitting of $\mathrm{CO}_{2}$, density, and composition of gas mixtures (at $32{ }^{\circ} \mathrm{C}$ ) is presented in Figure 7. The Fermi diad splitting increases with the density of the gas mixture and the content of $\mathrm{CO}_{2}$. Note that the shape of the curve with $99.8 \% \mathrm{CO}_{2}$ is relatively irregular between 103.7 and $104.3 \mathrm{~cm}^{-1}\left(0.3-0.7 \mathrm{~g} \cdot \mathrm{cm}^{-3}\right)$. This is likely due to the proximity with the critical temperature of $\mathrm{CO}_{2}\left(31.05{ }^{\circ} \mathrm{C}\right)$ where a small temperature fluctuation may result in a significant variation of density.

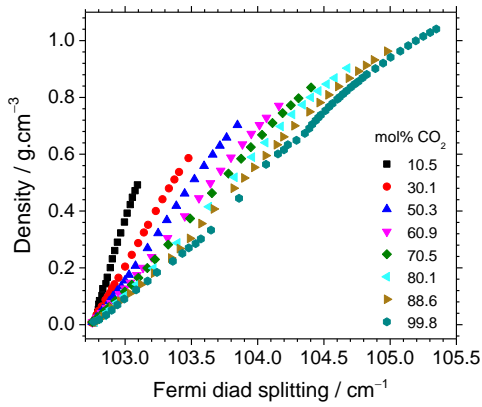

Figure 7: Evolution of the Fermi diad splitting of $\mathrm{CO}_{2}$ as a function of composition and density of $\mathrm{CO}_{2}-\mathrm{N}_{2}$ gas mixtures at $32{ }^{\circ} \mathrm{C}$. The density was calculated at given temperature, pressure, and composition by the GERG-2004 EoS. Uncertainty on density is smaller than data dot size.

Overall, the data of the present study are in good agreement with recently published densimeters of pure $\mathrm{CO}_{2} \cdot{ }^{39,40}$ It also agrees well with the previous investigations regarding the Fermi resonance of $\mathrm{CO}_{2}$ : (i) with increasing pressure, the Fermi resonance interaction reduces through a decrease of the anharmonic coupling constant $\left(\mathrm{k}_{122}\right)$, resulting in an increase of the separation between the unperturbed levels $\left(v_{1}\right.$ and $\left.2 v_{2}\right)$ as well as the Fermi diad splitting, ${ }^{56-58}$ and (ii) while increasing the content of $\mathrm{N}_{2}$, the reduction of the Fermi resonance becomes smaller (so the Fermi diad splitting still increases but with a smaller magnitude) in comparison with that of pure $\mathrm{CO}_{2}$ in the same conditions. ${ }^{57}$

c. Effect of temperature on the Fermi diad splitting of $\mathrm{CO}_{2}$

The effect of temperature on the variation of $\mathrm{CO}_{2}$ Fermi diad splitting of $\mathrm{CO}_{2}-\mathrm{N}_{2}$ gas mixtures was also analyzed conducting experiments at $22{ }^{\circ} \mathrm{C}$. At this temperature, a V-L phase transition is observed for any gas mixture containing > $92 \mathrm{~mol} \%$ $\mathrm{CO}_{2}$ (Figure 8a). The results are compared with those obtained at $32{ }^{\circ} \mathrm{C}$ in Figure $8 \mathrm{~b}$ and Figure 8c. In general, the magnitude of the variation of the $\mathrm{CO}_{2}$ Fermi diad splitting at $32{ }^{\circ} \mathrm{C}$ is smaller than that at $22{ }^{\circ} \mathrm{C}$ at the same pressure (Figure $8 \mathrm{~b}$ ) but identical at the same density (Figure 8c). A large gap appears at $\sim 60$ bars on the curve of pure $\mathrm{CO}_{2}$ at $22^{\circ} \mathrm{C}\left(<T_{\mathrm{c}}=31.05{ }^{\circ} \mathrm{C}\right)$ due to the vapor-liquid phase transition. Indeed, at this condition $\left(22{ }^{\circ} \mathrm{C}\right.$ and 60 bars), $\mathrm{CO}_{2}$ is in the two-phase LV domain (Figure 8a), and thus both liquid and vapor phases coexist in the microcapillary. Pressure remains constant at $\sim 60$ bars until the vapor phase is completely converted to liquid. As a result, no data point can be recorded within the density range $\sim 0.2 \mathrm{~g} \cdot \mathrm{cm}^{-3}$ (vapor state) to $\sim 0.7 \mathrm{~g} \cdot \mathrm{cm}^{-3}$ (liquid state). At 32 ${ }^{\circ} \mathrm{C}$, there is no phase transition (supercritical state) for any $\mathrm{CO}_{2}-$ $\mathrm{N}_{2}$ gas mixture (Figure 8a) and data points can be collected over the entire density range. Therefore, only the data acquired at 32 ${ }^{\circ} \mathrm{C}$ were fitted to provide calibration equations. These equations must be used at $32{ }^{\circ} \mathrm{C}$ only for pressure determination but can be used (at least) in the range $22-32{ }^{\circ} \mathrm{C}$ for density determination of any gas composition above the critical temperature (Figure 8b and Figure 8c).
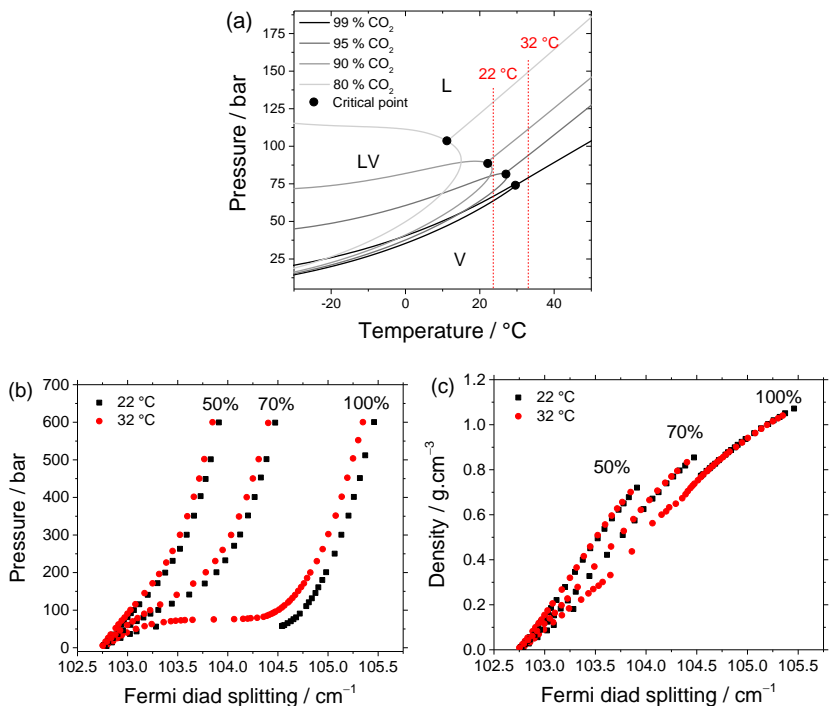

Figure 8: (a) Phase diagrams of $\mathrm{CO}_{2}-\mathrm{N}_{2}$ gas mixtures exported from data calculated by REFPROP. L: liquid-phase domain; V: vaporphase domain and LV: biphasic liquid-vapor domain. Only critical isochores are drawn for each mixture. (b) and (c) Comparison between the evolution of Fermi diad splitting of pure $\mathrm{CO}_{2}$ and $\mathrm{CO}_{2-}$ $\mathrm{N}_{2}$ mixtures (50 and $70 \mathrm{~mol} \% \mathrm{CO}_{2}$ ) as a function of pressure and density at 22 and $32{ }^{\circ} \mathrm{C}$. 
d. Calibration equations to determine the pressure and density of $\mathrm{CO}_{2}-\mathrm{N}_{2}$ gas mixtures

According to the whole data set shown in Figure 5, Figure 6 and Figure 7, the Fermi diad splitting of $\mathrm{CO}_{2}$ appears as the most reliable quantitative parameter for determining pressure and density of $\mathrm{CO}_{2}-\mathrm{N}_{2}$ gas mixtures. Data obtained at $32{ }^{\circ} \mathrm{C}$ were fitted to provide calibration equations. In order to minimize uncertainties on the calculated pressure and density, the calibration data were fitted separately for five smaller pressurecomposition ( $P X)$ domains (Figure 9). Regions (a) and (b) cover the pressure range 5 to 600 bars and the composition range 50 $100 \mathrm{~mol} \% \mathrm{CO}_{2}$ and $10-50 \mathrm{~mol} \% \mathrm{CO}_{2}$, respectively. Regions (c), (d) and (e) cover only the low-pressure range (5 - 150 bars) and the composition range $90-100 \mathrm{~mol} \% \mathrm{CO}_{2}, 30-90 \mathrm{~mol} \%$ $\mathrm{CO}_{2}$ and $10-30 \mathrm{~mol}_{\%} \mathrm{CO}_{2}$, respectively.

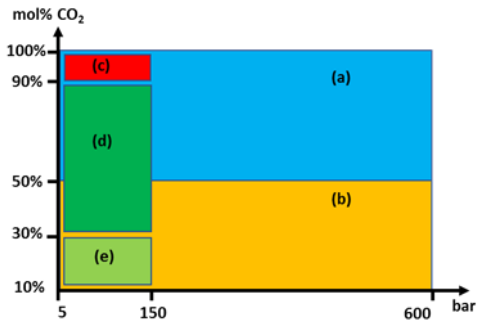

Figure 9: Pressure-composition $(P X)$ domains for application of polynomial equations a, b, c, d, and e. Experimental data were fitted within each $P X$ domain to provide the best-fitting polynomial equation to minimize uncertainties on the calculated pressure and density.

Third-order polynomial equations linking pressure or density to the $\mathrm{CO}_{2}$ Fermi diad splitting and the composition of gas mixtures were computed for each $P X$ domain. The general form of the calibration polynomial is given in Equation 3, where $C_{\mathrm{CO} 2}$ and $\Delta$ are defined by Equations 4 and 5, respectively. Fitting by a higher-order polynomial does not lead to substantial improvements in the qualitative of measurement. The coefficients $\left(p_{i j}, a, b, s t d \_a, s t d \_b\right.$, with $\left.(i+j) \leq 3\right)$ of each calibration equations are listed in Table S2 (pressure) and Table S3 (density) in Supporting Information.

$$
\begin{array}{lc}
\text { Pressure (or density) }=\sum_{i=0}^{3} \sum_{j=0}^{3} p_{i j} C_{\mathrm{CO}_{2}}^{i} \Delta^{j} & \text { Eq. } 3 \\
C_{\mathrm{CO}_{2}}=\frac{\text { Molar proportion of } \mathrm{CO}_{2}-a}{\text { Std_ } a} & \text { Eq. } 4 \\
\Delta=\frac{\text { Fermi diad splitting }-b}{\text { Std_b } b} & \text { Eq. } 5
\end{array}
$$

Two main error sources contribute to the final uncertainty of the calculated pressure and density. The first source is directly associated with the uncertainty of the Fermi diad splitting $( \pm$ $0.015 \mathrm{~cm}^{-1}$ ) and of the measured composition of the gas mixture (calculated from RRSCS and peak areas with Equation 2). As the regression calibration equations are not linear, the uncertainty of the first error source is not constant but varies with the composition of the gas mixture and the $\mathrm{CO}_{2}$ Fermi diad splitting. The second error source is related to how well the bestfitted calibration equations reproduce the pressure and the density from a given $\mathrm{CO}_{2}$ Fermi diad splitting and gas mixture composition. The uncertainty of each calibration equation was derived from its prediction bounds (at $1 \sigma$ ) and reported in the last row of Tables S2 and S3. The ultimate uncertainty on measured pressure or density will be the sum of these two error sources, as reported by Fall et al. ${ }^{39}$ and Wang et al. ${ }^{40}$ for pure $\mathrm{CO}_{2}$.

Investigation of $\mathrm{CO}_{2}-\mathrm{N}_{2}$ natural fluid inclusions. The calibrations described above were applied to 15 natural $\mathrm{CO}_{2}-\mathrm{N}_{2}$ fluid inclusions trapped within a quartz sample from the Central
Alps (Switzerland). Composition, pressure, and density were compared with those derived from microthermometry.

Each FI was analyzed three times by microthermometry to determine the melting temperature $T_{\mathrm{m}}$ (car) and the homogenization temperature of the volatile phase $T_{\mathrm{h}}($ car) (Table $\mathrm{S} 1$ ). These phase transition temperatures were subsequently reported in the $V X$ diagram of Thiéry et al. ${ }^{54}$ to calculate the composition and molar volume (density) of the fluid inclusion. As the uncertainties arising from this $V X$ diagram are unknown, only the uncertainty of $\pm 0.1{ }^{\circ} \mathrm{C}$ of the heating-cooling stage to $T_{\mathrm{m}}$ (car) and $T_{\mathrm{h}}$ (car) is considered. This uncertainty of $\pm 0.1{ }^{\circ} \mathrm{C}$ can cause either significant or insignificant error depending on the region in the $V X$ diagram. For example, the slopes of the $T_{\mathrm{h}}(\mathrm{car})$ lines are less steep in the vapor field than in the liquid field (Figure $\left.8 \mathrm{~b} \mathrm{in}^{54}\right)$. In this domain, an uncertainty of $\pm 0.1{ }^{\circ} \mathrm{C}$ in $T_{\mathrm{m}}$ (car) can result in a variation of up to $5 \mathrm{~mol} \%$ in composition and up to $0.09 \mathrm{~g} \cdot \mathrm{cm}^{-3}$ in density. The second source of error may be an error in graphical reading. Detailed microthermometry results of each FI were reported in Supporting Information (Table S1).

The selected FIs were also analyzed three times by Raman spectroscopy. The averaged values of the peak position and peak area of $\mathrm{CO}_{2}$ and $\mathrm{N}_{2}$ bands were used to calculate composition, pressure, and density through Equations 2 to 5. The composition of the FIs was calculated by the RRSCS of the two $\mathrm{CO}_{2}$ bands and their sum for comparison. The difference between these three values is always less than $1 \mathrm{~mol} \% \mathrm{CO}_{2}$. Detailed measurements of each FI are presented in Table S4 of Supporting Information.
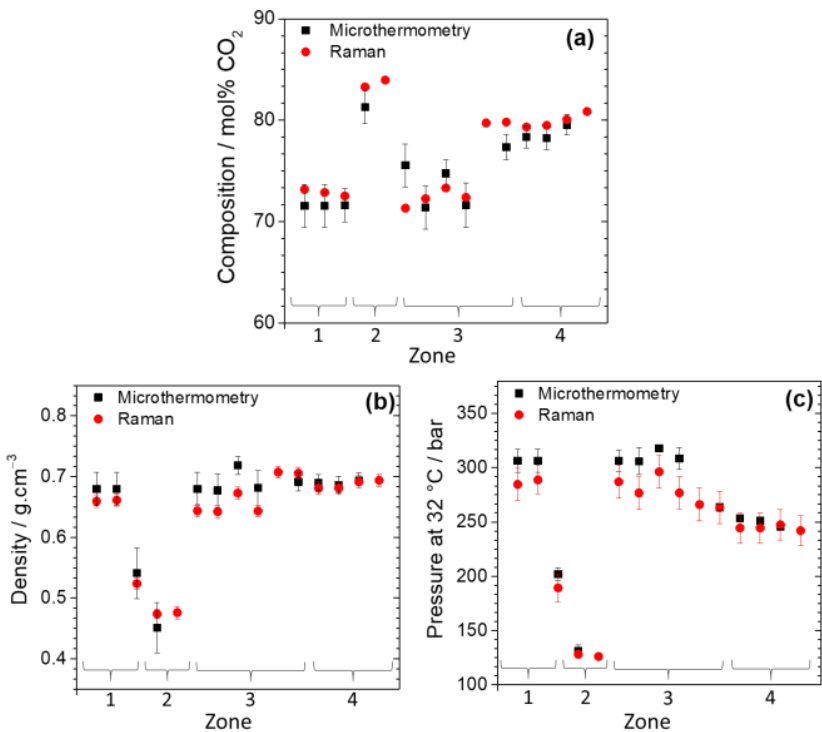

Figure 10: Comparison after analysis of the volatile phase of selected FIs by Raman and microthermometry of the (a) composition, (b) density, and (c) pressure at $32{ }^{\circ} \mathrm{C}$.

Figure 10 presents a comparison between Raman and microthermometry results. The uncertainty of Raman measurements on composition $\left(<0.5 \mathrm{~mol} \% \mathrm{CO}_{2}\right)$ and density $(<0.01$ $\mathrm{g} \cdot \mathrm{cm}^{-3}$ ) is slightly better than that derived from microthermometry measurements (ranging from $\sim 1$ to $2.2 \mathrm{~mol} \%$ for composition, and from 0.01 to $0.04 \mathrm{~g} \cdot \mathrm{cm}^{-3}$ for density). Uncertainty on measured pressure at $32{ }^{\circ} \mathrm{C}$ from microthermometry (varying from 2 to 11 bars, Figure 10c) is equivalent to that from Raman $(\sim 15$ bars when pressure $>150$ bars, and $\sim 3$ bars when pressure $<150$ bars).

Overall, the results derived from the two methods are close and comparable with a relative difference varying from $0.1-7$ 
$\%$ coming from the error sources mentioned above, but also from the unknown error of the thermodynamic models of Soave-Redlich-Kong (1972) and Lee-Kesler (1975) used for the construction of the $V X$ diagram of Thiéry et al. (1994). ${ }^{54}$ According to Mullis et al. ${ }^{47}$, the trapping temperature of the geological fluid where $\mathrm{Mu} 147.2$ sample was collected was about $400{ }^{\circ} \mathrm{C}$. Thereby, the trapping pressure (the pressure at trapping temperature) of the geological fluid determined using GERG-2004 EoS is about $1610 \pm 20$ bar (calculated from Raman results) or $1770 \pm 20$ bars (calculated from microthermometry results). The difference of density leads to a difference of only 160 bars $(9 \%)$ which is of no consequence on geological interpretation.

Raman spectroscopy may be more efficient than microthermometry in some cases. For example, FI4.8 is too small $(<2$ $\mu \mathrm{m}$, Figure 3a) to observe any phase transition with good accuracy. Concerning FI3.5, $T_{\mathrm{h}}(\mathrm{car})$ could not be determined precisely because the vapor bubble was located in the dark part of the inclusion at a temperature close to homogenization (Figure 3b). Similarly, FI2.2 could not be analyzed by microthermometry because of bad optical conditions (color, contrast, etc.). These three FIs could, however, be analyzed by Raman spectroscopy. Another disadvantage of microthermometry method (using $V X$ diagram of Ref. ${ }^{54}$ ) appears when clathrate is formed and remains above $T_{\mathrm{h}}(\mathrm{car})$, meaning that a part of $\mathrm{CO}_{2}$ is still trapped inside the clathrate structure, and thus could lead to an underestimation of the $\mathrm{CO}_{2}$ quantity while using only $T_{\mathrm{h}}$ (car). ${ }^{59,60}$ The latter problem is not encountered by Raman spectroscopy at 22 and $32{ }^{\circ} \mathrm{C}$.

\section{CONCLUSION}

The use of an improved HPOC system consisting of an FSC coupled with a heating-cooling stage and a Raman spectrometer makes it possible to investigate the behavior of $\mathrm{CO}_{2}-\mathrm{N}_{2}$ mixtures at controlled pressure and temperature conditions. The experiments can be easily repeated several times for statistical purposes as well as repeatability and reproducibility test. A complete calibration of the Raman signals of $\mathrm{CO}_{2}-\mathrm{N}_{2}$ mixtures was thus performed for the first time. The Fermi diad splitting of $\mathrm{CO}_{2}$ was linked to pressure or density for any $\mathrm{CO}_{2}-\mathrm{N}_{2}$ gas mixture in the range $22-32{ }^{\circ} \mathrm{C}$. It was also demonstrated that the RRSCS of $\mathrm{CO}_{2}$ does not depend on composition but slightly on pressure or density. However, this effect is negligible in the studied pressure range ( $<600$ bar). Thus accurate RRSCS values of the two vibration modes of $\mathrm{CO}_{2}$ and their sum can be either used to determine the composition of $\mathrm{CO}_{2}-\mathrm{N}_{2}$ gas mixtures with an uncertainty of about $\pm 0.5 \mathrm{~mol} \%$. The pressure and the density of $\mathrm{CO}_{2}-\mathrm{N}_{2}$ binary gas mixtures can be henceforth calculated by using regression calibration equations that were validated by successful application to natural fluid inclusions from the Central Alps, Switzerland. A detailed comparison was made indicating that Raman spectroscopy is a powerful alternative tool to the microthermometry, providing not only $P V X$ information with comparable accuracy (even better in some cases) but also handling cases for which microthermometry cannot be applied. This study shows the applicability of Raman spectroscopy for gas analysis purposes at extreme conditions (very small object at high pressure) and can be easily extended to any gas mixture.

\section{ASSOCIATED CONTENT}

\section{Supporting Information}

The Supporting Information is available free of charge on the ACS Publications website.
Detailed uncertainty calculations and the coefficients of regression polynomial equations 3,4 and 5 (PDF)

\section{AUTHOR INFORMATION}

\section{Corresponding Author}

*E-mail: van-hoan.le@univ-lorraine.fr

\section{Author Contributions}

All authors have approved the final version of the manuscript.

\section{ACKNOWLEDGMENTS}

This work is a part of the thesis of Van-Hoan Le (Universite de Lorraine) who acknowledges the French Ministry of Education and Research and the ICEEL Institut Carnot. The work benefited financial support from CNRS-INSU CESSUR program. The authors are sincerely thankful to Catherine Lorgeoux and Héloïse Verron for their instruction during the Gas Chromatography measurement part, to Silvia Lasala and Romain Privat for a fruitful discussion about the thermodynamic properties of the $\mathrm{CO}_{2}-\mathrm{N}_{2}$ system. Two anonymous reviewers are acknowledged for their thorough review and their insightful comments and suggestions.

\section{REFERENCES}

(1) D’Orazio, M.; Hirschberger, R. Opt. Eng. 1983, 22 (3), 308.

(2) Petrov, D. V.; Matrosov, I. I. Appl Spectrosc 2016, 70 (10), 1770-1776.

(3) Hanf, S.; Keiner, R.; Yan, D.; Popp, J.; Frosch, T. Anal. Chem. 2014, 86 (11), 5278-5285.

(4) Hanf, S.; Bögözi, T.; Keiner, R.; Frosch, T.; Popp, J. Anal. Chem. 2015, 87 (2), 982-988.

(5) Inaba, H.; Kobayasi, T. Nature 1969, 224 (5215), 170.

(6) Buric, M. P.; Chen, K.; Falk, J.; Velez, R.; Woodruff, S. 2009; Vol. 7316, p 731608 .

(7) Kiefer, J.; Seeger, T.; Steuer, S.; Schorsch, S.; Weikl, M. C.; Leipertz, A. Meas. Sci. Technol. 2008, 19 (8), 085408.

(8) Petrov, D. V.; Matrosov, I. I.; Zaripov, A. R.; Maznoy, A. S. Spectroc. Acta A 2019, 215, 363-370.

(9) Bögözi, T.; Popp, J.; Frosch, T. Bioanalysis 2015, 7 (3), 281284.

(10) Jochum, T.; Rahal, L.; J. Suckert, R.; Popp, J.; Frosch, T. Analyst 2016, 141 (6), 2023-2029.

(11) Pedeche, S.; Simon, P.; Matzen, G.; Moulin, B.; Blanchard, K.; Querel, G. J. Raman Spectrosc. 2003, 34 (3), 248-252.

(12) Taquet, N.; Pironon, J.; De Donato, P.; Lucas, H.; Barres, O. Int. J. Greenhouse Gas Control 2013, 12, 359-371.

(13) Jochum, T.; von Fischer, J. C.; Trumbore, S.; Popp, J.; Frosch, T. Anal. Chem. 2015, 87 (21), 11137-11142.

(14) Jochum, T.; Fastnacht, A.; Trumbore, S. E.; Popp, J.; Frosch, T. Anal. Chem. 2017, 89 (2), 1117-1122.

(15) Keiner, R.; Herrmann, M.; Küsel, K.; Popp, J.; Frosch, T. Analytica Chimica Acta 2015, 864, 39-47.

(16) Sieburg, A.; Jochum, T.; Trumbore, S. E.; Popp, J.; Frosch, T. Analyst 2017, 142 (18), 3360-3369.

(17) Sieburg, A.; Schneider, S.; Yan, D.; Popp, J.; Frosch, T. Analyst 2018, 143 (6), 1358-1366.

(18) Roedder, E. Mineral. Soc. Am. 1984, 12, 644.

(19) Van den Kerkhof, A.; Thiéry, R. Lithos 2001, 55 (1), 49-68.

(20) Rosso, K. M.; Bodnar, R. J. Geochim Cosmochim Acta. 1995, 59 (19), 3961-3975.

(21) Kawakami, Y.; Yamamoto, J.; Kagi, H. Appl. Spectrosc. 2003, 57 (11), 1333-1339.

(22) Yamamoto, J.; Kagi, H.; Kaneoka, I.; Lai, Y.; Prikhod'ko, V. S.; Arai, S. Earth Planet. Sci. Lett. 2002, 198 (3), 511-519.

(23) Yamamoto, J.; Kagi, H.; Kawakami, Y.; Hirano, N.; Nakamura, M. Earth Planet. Sci. Lett. 2007, 253 (3), 369-377.

(26) Frezzotti, M. L.; Tecce, F.; Casagli, A. J. Geochem. Explor. 2012, 112 (Supplement C), 1-20. 

eralogy; 2012; Vol. 12, pp 83-172.

(28) Wopenka, B.; Pasteris, J. D. Appl. Spectrosc., AS 1986, 40 (2), 144-151.

(29) Fouche, D. G.; Chang, R. K. Appl. Phys. Lett. 1971, 18 (12), 579-580.

(30) Penney; Goldman; Lapp. Nat. Phys. Sci. 1972, 235, 110-112.

(31) Fenner, W. R.; Hyatt, H. A.; Kellam, J. M.; Porto, S. P. S. J. Opt. Soc. Am., JOSA 1973, 63 (1), 73-77.

(32) Schrötter, H. W.; Klockner. In Topics in Current Physics; 1979; Vol. 11, pp 123-164.

(33) Seitz, J. C.; Pasteris, J. D.; Chou, I.-M. Am. J. Sci. 1993, 293 (4), 297-321.

(34) Seitz, J. C.; Pasteris, J. D.; Chou, I.-M. Am. J. Sci. 1996, 296 (6), 577-600.

(35) Dubessy, J.; Poty, B.; Ramboz, C. Eur. J. Mineral. 1989, 517534.

(36) Wang, C. H.; Wright, R. B. J. Chem. Phys. 1973, 59 (4), 1706-1712.

(37) Garrabos, Y.; Chandrasekharan, V.; Echargui, M. A.; Marsault-Herail, F. Chem. Phys. Lett. 1989, 160 (3), 250-256.

(38) Wright, R. B.; Wang, C. H. J. Chem. Phys. 1974, 61 (7), 2707-2710.

(39) Fall, A.; Tattitch, B.; Bodnar, R. J. Geochim Cosmochim Acta. 2011, 75 (4), 951-964.

(40) Wang, X.; Chou, I.-M.; Hu, W.; Burruss, R. C.; Sun, Q.; Song, Y. Geochim Cosmochim Acta. 2011, 75 (14), 4080-4093.

(41) Lamadrid, H. M.; Steele-Macinnis, M.; Bodnar, R. J. Raman Spectrosc. 2017.

(42) Yamamoto, J.; Kagi, H. Chem. Lett. 2006, 35 (6), 610-611.

(43) Lamadrid, H. M.; Moore, L. R.; Moncada, D.; Rimstidt, J. D.; Burruss, R. C.; Bodnar, R. J. Chem. Geol. 2017, 450, 210222.
(44) Chou, I.-M.; Burruss, R. C.; Lu, W. In Advances in HighPressure Technology for Geophysical Applications; Chen, J., Wang, Y., Duffy, T. S., Shen, G., Dobrzhinetskaya, L. F., Eds.; Elsevier: Amsterdam, 2005; pp 475-485.

(45) Chou, I.-M. In EMU Notes in Mineralogy; 2012; Vol. 12, pp 227-247.

(46) Caumon, M.-C.; Robert, P.; Laverret, E.; Tarantola, A.; Randi, A.; Pironon, J.; Dubessy, J.; Girard, J.-P. Chem. Geol. 2014, 378 (Supplement C), 52-61.

(47) Mullis, J.; Dubessy, J.; Poty, B.; O’Neil, J. Geochim Cosmochim Acta. 1994, 58 (10), 2239-2267.

(48) Caumon, M.-C.; Dubessy, J.; Robert, P.; Tarantola, A. Eur. J. Mineral. 2013, 25 (5), 755-763.

(49) McCreery, R. L. Raman Spectroscopy for Chemical Analysis; John Wiley \& Sons, 2005; Vol. 225.

(50) Bendtsen, J. Journal of Raman Spectroscopy 1974, 2 (2), 133 145 .

(51) Kramida, A.; Ralchenko, Y.; Reader, J.; NIST ASD Team. NIST Atomic Spectra Database (version 5.6.1); 2018.

(52) Fermi, E. Z. Physik 1931, 71 (3-4), 250-259.

(53) Placzek, G. Rayleigh-Streuung und Raman-Effekt; Akad. Verlag-Ges., 1934; Vol. 2.

(54) Thiéry, R.; Kerkhof, A.; Dubessy, J. Eur. J. Mineral. 1994, 6, 753-771.

(55) Lemmon, E. W.; Huber, M. L.; McLinden, M. O. Standard Reference Data Program, Gaithersburg 2013.

(56) Hacura, A.; Bródka, A.; Nikiel, L.; Baglin, F. G. J. Mol. Struct. 1990, 218, 297-302.

(57) Hacura, A. Phys. Lett. A 1997, 227 (3-4), 237-240.

(58) Olijnyk, H.; Däufer, H.; Jodl, H. -J.; Hochheimer, H. D. J. Chem. Phys. 1988, 88 (7), 4204-4212.

(59) Diamond, L. W. Geochim Cosmochim Acta. 1992, 56 (1), 273-280.

(60) Bakker, R. J. Computers \& Geosciences 1997, 23 (1), 1-18.

For Table of Contents Only

From Raman spectral variation To quantitative information
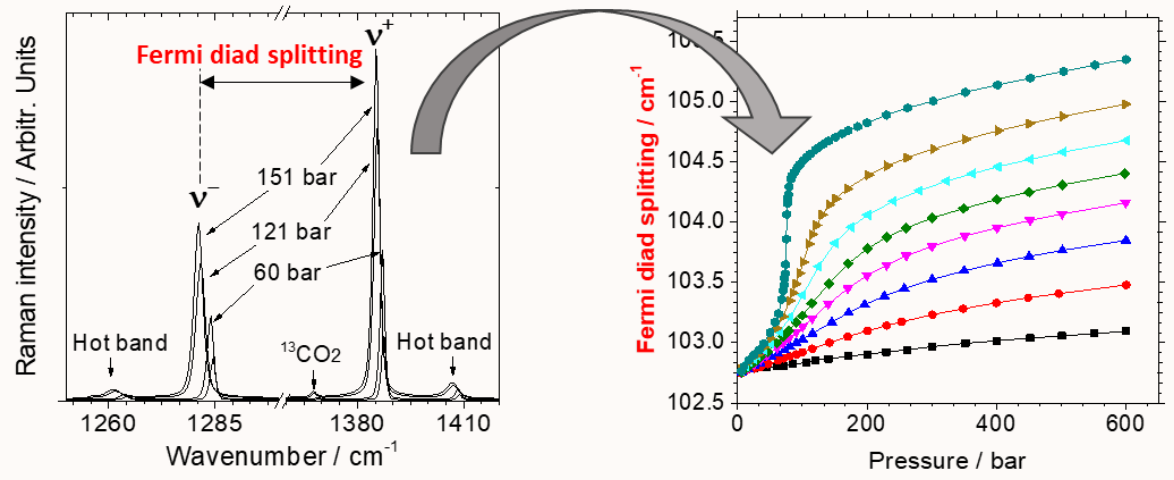

$99.8 \mathrm{~mol} \% \mathrm{CO}$ $88.6 \mathrm{~mol} \% \mathrm{CO}$ $70.5 \mathrm{~mol} \% \mathrm{CO}$ $60.9 \mathrm{~mol} \% \mathrm{CO}$ $50.3 \mathrm{~mol} \% \mathrm{CO}$ $30.1 \mathrm{~mol} \% \mathrm{CO}_{2}$ $10.5 \mathrm{~mol} \% \mathrm{CO}_{2}$ 